\title{
Escala de avaliação das estratégias de aprendizagem (ensino profissionalizante): Adaptação e estudos psicométricos
}

\section{RESUMO}

O objetivo deste estudo foi investigar as propriedades psicométricas da Escala de Avaliação das Estratégias de Aprendizagem para alunos do Ensino Profissionalizante (EAVAP-EP). Esta escala foi adaptada do contexto do ensino fundamental para o ensino profissionalizante por meio de um estudo focal com cinco professores e 11 alunos. A evidência de validade de conteúdo da EAVAP-EP foi investigada mediante a análise de seis juízes especialistas e estudo piloto com 24 alunos que indicaram a representatividade e a compreensão dos itens adaptados. A evidência de validade baseada na estrutura interna da EAVAP-EP foi obtida com uma amostra de 401 alunos. A análise de componentes principais indicou a variância explicada de $31,37 \%$ da escala. Os 28 itens foram distribuídos em três dimensões: cognitivas, metacognitivas e metacognitivas disfuncionais, com cargas fatoriais acima de 0,30. Verificou-se, ainda, a estimativa de fidedignidade da EAVAP-EP (escala total: $\alpha=0,86)$. Sugere-se a utilização da EAVAP-EP no contexto do ensino profissionalizante e a continuidade das pesquisas com o instrumento.

Palavras-chave: Estratégias cognitivas; Estratégias metacognitivas; Avaliação psicoeducacional.

\section{INTRODUÇÃO}

O Ensino Profissionalizante (EP) tem por objetivo formar o aluno para o desempenho de profissões de nível técnico. Esta modalidade de ensino vem ganhando visibilidade no Brasil como uma política que busca atender às demandas socioeconómico-ambientais. 0 EP é muito procurado devido à sua duração ser mais breve e os custos mais baixos em comparação a um curso de nível superior. Para os alunos mais jovens, o EP pode ser uma alternativa para conseguir um emprego, enquanto que, para os alunos mais velhos, cursar este tipo de ensino configura-se como meio de melhorar as suas qualificações profissionais e de reinserção no mercado de trabalho (Brasil, 2012, 2018).

Diferente do que ocorre com os níveis de Ensino Básico e Superior, a grelha curricular desta modalidade de ensino confere maior ênfase ao

\author{
Carla Priscila da Silva \\ Pereira ${ }^{i}$ \\ Universidade São \\ Francisco, Campus de \\ Campinas/SP, Brasil \\ Acácia Aparecida Angeli \\ dos Santos ${ }^{i i}$ \\ Universidade São \\ Francisco, Campus de \\ Campinas/SP, Brasil \\ Adriana Satico Ferraz ${ }^{\text {iii }}$ \\ Universidade São \\ Francisco, Campus de \\ Campinas/SP, Brasil
}


desenvolvimento de habilidades específicas de profissões técnicas, a partir da execução de tarefas práticas. A interdisciplinaridade do EP exige da Instituição de Ensino o desenvolvimento e a aplicação de estratégias pedagógicas que possibilitem a compreensão dos alunos acerca da proposta desta modalidade de ensino, centralizada na integração dos aspetos teóricos com a prática profissional (Slaats et al., 1999). Por sua vez, é exigida do aluno uma certa flexibilidade para que se faça a sua adaptação às situações de aprendizagem, que o aproximam da realidade do exercício profissional e que costumam ocorrer num curto período de tempo (Brasil, 2012, 2018; Jossberger et al., 2019; Slaats et al., 1999).

Uma forma de lidar com as demandas inerentes às especificidades do EP é agregar aos recursos pedagógicos o uso de estratégias de aprendizagem cognitivas e metacognitivas. Estas estratégias são definidas como sequências integradas de procedimentos ou atividades que visam otimizar a aquisição, o armazenamento e a utilização do conteúdo transmitido ao aluno (Jossberger et al., 2019; Pozo, 1996). As estratégias cognitivas são utilizadas pelos alunos de modo intencional na execução das atividades académicas, ajudando-os a procurar pela informação, o que envolve o ensaio, a elaboração e a organização (ex.: anotar o conteúdo das aulas) (Boruchovitch, 1999; Cash, 2016; Dembo \& Eaton, 2000; Jossberger et al., 2019; Liu, 2009; Oliveira et al., 2010). Por sua vez, as estratégias de aprendizagem metacognitivas estão relacionadas com a regulação dos aspetos cognitivos e afetivos. São procedimentos que o aluno aplica para planear, organizar, monitorizar e regular o próprio pensamento e a habilidade de aprender a aprender sobre as diversas possibilidades de realizar com êxito as tarefas do curso profissionalizante (ex.: simular situações para recriar o conteúdo aprendido) (Boruchovitch,1999; Cash, 2016; Dembo \& Eaton, 2000; Flavell,1979; Oliveira et al., 2010; Pozo, 1996).

Especialmente no que diz respeito ao processo de ensino e aprendizagem, conjetura-se que o uso adequado destas estratégias pode auxiliar os alunos de cursos profissionalizantes na sua rotina de estudos. Isto porque, nos diversos níveis de ensino, quando as estratégias de aprendizagem são bem aplicadas pelos alunos, tendem a facilitar a realização das atividades e contribuir para o bom desempenho académico (Costa \& Boruchovitch, 2015; Kikas \& Jõgi, 2015; Jossberger et al., 2019; Santos \& Alliprandini, 2017). A título de exemplo, intervenções com o objetivo de desenvolver as estratégias de aprendizagem na educação básica em vários domínios e disciplinas (ex.: escrita e biologia) resultaram num aumento no repertório de estratégias, acrescida da eficácia na sua utilização constatada na elevação do desempenho dos alunos (Costa \& Boruchovitch, 2015; Santos \& Alliprandini, 2017). 0 estímulo à utilização de estratégias de aprendizagem também foi preditor do bom desempenho em leitura, compreensão de leitura e em matemática ao longo dos anos escolares (Kikas \& Jõgi, 2015).

Ao fazer uma comparação com os alunos do Ensino Superior, Slaats et al. (1999) já indicavam a existência de diferenças nos tipos de estratégias de aprendizagem empregadas pelos alunos do EP em decorrência das particularidades desse público, bem como pelas distinções desses ambientes educacionais. Esses autores observaram que os alunos do EP eram menos estimulados a refletir sobre o próprio comportamento, o que pode ter impactado 
na verbalização de um número menor de estratégias, em relação aos alunos do Ensino Superior. Ao analisar os tipos de estratégias utilizadas na aprendizagem teórica e prática exigidas no EP, os alunos desta modalidade de ensino apresentaram tanto o uso de procedimentos mais superficiais (ênfase cognitiva), centralizados na reprodução literal dos conteúdos das aulas (ex.: reler a matéria), como o emprego de métodos mais profundos (ênfase metacognitiva), que exigiam a compreensão e a elaboração sobre o tema abordado (ex.: parafrasear os textos).

No EP existem indícios de que os alunos utilizam mais as estratégias cognitivas de aprendizagem, direcionadas à organização do tempo e à mobilização de recursos para realizar as tarefas do curso. As estratégias metacognitivas tendem a ser aplicadas pelos alunos para automonitorizar as suas ações com foco no alcance de bons resultados (Jossberger et al., 2019). Num sentido mais amplo, as estratégias metacognitivas são preditivas da satisfação do aluno com o curso profissionalizante. Ao comparar alunos matriculados e egressos, essa relação é maior para os alunos que finalizaram o curso, sugerindo que as estratégias de aprendizagem, voltadas para a automonitorização e autorregulação, estão relacionadas com a qualidade da formação e quanto ela os capacita para a atuação profissional (Oliveira, Teixeira, \& Santos, 2019).

Posto isto, o presente estudo teve por objetivo a adaptação e a investigação das propriedades psicométricas da Escala de Avaliação das Estratégias de Aprendizagem para o Ensino Fundamental (EAVAP-EF; Oliveira et al., 2010) para o contexto do Ensino Profissionalizante no Brasil. A EAVAP-EF é um instrumento de autorrelato que avalia as estratégias cognitivas e metacognitivas de alunos do Ensino Fundamental em situações de estudo e aprendizagem.

Os estudos realizados com a EAVAP-EF têm ampliado o entendimento sobre a adoção de estratégias de aprendizagem nos níveis de Ensino Fundamental e Médio. No Ensino Fundamental, alunos com bom desempenho em Língua Portuguesa e Matemática apresentaram um repertório maior de estratégias de aprendizagem quando comparados àqueles com desempenho inferior (Cruvinel \& Boruchovitch, 2004). A incidência do uso de estratégias de aprendizagem também parece variar entre os sexos - as meninas afirmaram utilizar mais estratégias do que os meninos - e entre os ciclos do Ensino Fundamental - os alunos do primeiro ciclo apresentaram maior uso de estratégias do que os alunos do segundo ciclo (Oliveira et al., 2011). Ainda no Ensino Fundamental, os alunos que possuem a perceção de que o uso de estratégias cognitivas e metacognitivas está relacionado com as características de bons estudantes apresentaram um número maior de estratégias de aprendizagem em comparação aos alunos que não conseguiam realizar essa associação (Gomes \& Boruchovitch, 2005). Por sua vez, a EAVAP-EF acrescida de itens adaptados para o EP aplicada em alunos do Ensino Médio, permitiu verificar a ausência de estratégias metacognitivas disfuncionais. Este resultado tende a ser positivo, tendo em vista que a presença destas estratégias poderia prejudicar os alunos na preparação e realização das tarefas escolares. Estes alunos também utilizavam as estratégias cognitivas e metacognitivas de modo equiparável (Oliveira et al., 2017). 
No tocante ao EP, Scacchetti, Oliveira, e Moreira (2015) realizaram a adaptação da EAVAP-EF para esta modalidade de ensino. No entanto, o estudo psicométrico inicial com a versão adaptada indicou baixo índice de consistência interna no fator Estratégias Metacognitivas $(\alpha=0,57)$, possivelmente pela dificuldade de aquilatar os aspetos da regulação, autoperceção e planeamento desta dimensão teórica. Perante este resultado, as autoras ponderam sobre a presença de eventuais problemas na adaptação da escala para a realidade do EP na dimensão das estratégias metacognitivas, visto que este tipo de ensino prioriza as estratégias cognitivas (ex.: repetição). Mediante o exposto, Scacchetti et al. (2015) apontam para a continuidade de estudos com a proposta de adaptar a EAVAP-EF para o EP, a fim de obter uma medida mais apropriada para a avaliação das estratégias de aprendizagem nessa modalidade de ensino, com especial atenção para as especificidades das estratégias metacognitivas.

Os estudos supracitados enfatizam o papel das estratégias no processo de aprendizagem e indicam a necessidade de investigá-las no EP. Enfatizase que instrumentos de medida apropriados a esse contexto de ensino podem fornecer apoio pedagógico às demandas específicas de aprendizagem dos alunos, sendo um recurso a ser utilizado, por exemplo, por psicólogos escolares (Titon \& Zanella, 2018). Estes aspetos reforçam a potencial contribuição do presente estudo, centralizada na adaptação dos itens da EAVAP-EF para o EP (Estudo 1), bem como na investigação das suas propriedades psicométricas iniciais, essenciais para que o instrumento seja aplicado em alunos desta modalidade de ensino (American Educational Research Association, American Psychological Association, \& National Conuncil on Measurement in Education [AERA, APA, \& NEME], 2014). Deste modo, pretende-se conferir a evidência de validade de conteúdo (Estudo 2), e a evidência de validade de consistência baseada na estrutura interna acrescida da investigação das estimativas de precisão para a versão adaptada da EAVAP-EF (Estudo 3).

\section{ESTUDO 1: MÉTODO, RESULTADOS E DISCUSSÃO}

Participaram da etapa de adaptação da EAVAP-EF cinco docentes do Ensino Profissionalizante, sendo $60 \%(n=3)$ do sexo masculino e $40 \%(n=2)$ do sexo feminino. Também compuseram a amostra 11 alunos de cursos profissionalizantes, a saber: Técnico em Enfermagem 18\% $(n=2)$, Logística 9\% ( $n=1)$, Estética 18\% ( $n=2)$, Massoterapia 27\% (n=1), e Podologia 28\% $(n=3)$. A maior parte da amostra era do sexo feminino $(n=10 ; 91 \%)$. Quanto à escolaridade, 64\% $(n=7)$ dos alunos tinham o Ensino Médio completo, 18\% $(n=2)$ possuíam o Ensino Superior completo e $18 \%(n=2)$ o Ensino Superior incompleto.

Neste estudo foram usados quatro instrumentos de coleta de dados, nomeadamente:

- Ficha de identificação (Pereira, 2016) - Teve por objetivo coletar as informações sociodemográficas dos participantes. Estas informações referiam-se ao nome, idade e sexo (docentes e alunos); tipo de curso profissionalizante e escolaridade (somente alunos); 
- Escala de Avaliação de Estratégias de Aprendizagem para o Ensino Fundamental (EAVAP-EF; Oliveira et al., 2010) - Esta escala possui 37 itens divididos em três fatores - Ausência de Estratégias Metacognitivas Disfuncionais, Estratégias Cognitivas e Estratégias Metacognitivas. A chave de resposta é tipo Likert de 3 pontos ("2 = sempre", "1 = às vezes" e " $0=$ nunca"). Os itens do fator Ausência de Estratégias Metacognitivas Disfuncionais devem ter a pontuação invertida. $\mathrm{O}$ instrumento pode ser aplicado de forma individual ou coletiva. A pontuação mínima da escala é de 0 pontos e a máxima de 74 pontos. A EAVAP-EF possui evidência de validade de consistência interna $(31,14 \%$ da variância explicada total) e estimativas de precisão - escala total e Fator Ausência de Estratégias Metacognitivas Disfuncionais, $\alpha=0,80$; Estratégias Cognitivas, $\alpha=0,74$; Estratégias Metacognitivas, $\alpha=0,62$; e evidência de validade de critério concorrente, tendo como variável de critério o rendimento escolar representado pelo desempenho nas disciplinas de Língua Portuguesa e Matemática;

- Roteiro para a entrevista com os professores (Pereira, 2016) Composto por quatro itens referentes às sugestões dadas pelo professor aos alunos, sobre o uso de estratégias de aprendizagem, a fim de auxiliá-los no curso; apresentação da EAVAP-EF aos professores; avaliação da compatibilidade do conteúdo dos itens da escala para os alunos do ensino profissionalizante; e sugestões dos professores de estratégias de aprendizagem utilizadas pelos alunos e que não constavam nos itens da escala;

- Roteiro para a discussão do grupo focal com os alunos (Pereira, 2016) - Possui 6 itens que visam o acesso às estratégias de aprendizagem utilizadas pelos alunos do ensino profissionalizante. 0 conteúdo destes itens abarca os aspetos teóricos e práticos do curso.

Mediante a autorização para a realização da presente pesquisa por uma Instituição de Ensino Privada do interior de São Paulo que oferece o Ensino Profissional Técnico de Nível Médio, a proposta de pesquisa foi encaminhada e aprovada pelo Comitê de Ética em Pesquisa da Universidade à qual está vinculada (CAAE: 41689415.2.00005514; Parecer de aprovação no 971.269). Na recolha de dados, seguiram-se todos os procedimentos éticos para pesquisas com seres humanos previstas pela Resolução CNS 510/2016 do Conselho Nacional de Saúde (Brasil, 2016). O procedimento de recolha de dados com os professores englobou o convite, o agendamento daqueles que aceitaram participar da pesquisa e a autorização do docente por meio da sua assinatura no Termo de Consentimento Livre e Esclarecido (TCLE).

Aplicou-se a Ficha de Identificação e o Roteiro para a entrevista com os professores. Em seguida, solicitou-se que os professores avaliassem a adequação dos itens da EAVAP-EF em relação às estratégias que os alunos utilizam ou deveriam utilizar no processo de aprendizagem. Os profissionais foram convidados a sugerir outras estratégias utilizadas no ensino profissionalizante que não estivessem contempladas na escala, observando principalmente o conteúdo prático que é característico desta modalidade de ensino. 
Por fim, foi-lhes perguntado a respeito da compreensão dos itens, indagando se a forma como estavam descritos favorecia o entendimento pela população à qual se destina.

As entrevistas foram gravadas com autorização dos participantes, e ao final cada professor indicou dois alunos para participar do grupo focal. 0 procedimento de recolha de dados com os alunos abarcou a assinatura destes no TCLE. Realizaram-se três grupos focais com cerca de quatro alunos cada. A duração de cada grupo foi de 30 minutos e as discussões foram conduzidas seguindo o Roteiro para a discussão do grupo focal com os alunos. A EAVAPEF não foi apresentada aos alunos para não interferir nas suas sugestões de estratégias.

Após a transcrição das entrevistas com os professores e alunos, os dados foram avaliados qualitativamente, por meio de análise do seu conteúdo. Todos os comentários que sugeriram o uso de estratégias de aprendizagem foram organizados numa planilha de dados, item a item.

As entrevistas com os professores resultaram em 65 sugestões de estratégias de aprendizagem. Após a exclusão das estratégias repetidas, permaneceram 41 sugestões. No tocante à EAVAT-EF, não houve objeções dos professores aos itens da escala. Todavia, os profissionais sugeriram o acréscimo de itens relacionados com a execução prática de procedimentos, devido ao facto de as aulas do EP serem focadas em metodologias ativas que proporcionam a ação-reflexão-ação (Brasil, 2018). Alguns exemplos de itens sugeridos pelos professores foram: "pesquisar aplicações dos conteúdos para a prática profissional"; "praticar em casa as técnicas que aprendem em sala de aula"; e "observar atentamente as práticas realizadas em sala de aula".

Por sua vez, os relatos do grupo focal totalizaram 51 estratégias de aprendizagem (já com a exclusão dos itens repetidos). Foram exemplos de estratégias listadas pelos alunos: "reescrever em casa o conteúdo de sala de aula" e "fazer projetos que aplique o conteúdo teórico em situações práticas reais ou simuladas".

As estratégias de aprendizagem indicadas por professores e alunos foram comparadas e organizadas numa única lista. Com a unificação dos itens semelhantes contidos nas duas listas, foram identificadas 52 estratégias de aprendizagem, que foram comparadas com o conteúdo da EAVAP-EF. Com base nesta comparação, foram excluídas as sugestões de estratégias que apresentavam conteúdo análogo aos itens da escala, tais como "Estudar em cima da hora"; "Anotar a explicação"; "Verificar se errou"; "Ler sobre o assunto que o professor explicou"; "Ler e sublinhar o que é importante no texto"; "Fazer resumos"; "Elaborar questões sobre o conteúdo a ser aprendido"; "Fazer relações do conteúdo com outros vistos anteriormente". No final, permaneceram 42 sugestões de estratégias de aprendizagem que fundamentaram a elaboração de 13 novos itens para compor a EAVAP-EF na versão para o Ensino Profissionalizante - EAVAP-EP. Esses itens são apresentados na Tabela 1. 
Tabela 1

Itens Elaborados para Compor a EAVAP-EP

\begin{tabular}{|c|c|c|}
\hline \multicolumn{2}{|r|}{ Itens } & Classificação \\
\hline 1 & $\begin{array}{l}\text { Para aprender mais você costuma revisar as técnicas } \\
\text { assistindo vídeo-aulas online? }\end{array}$ & Cognitiva \\
\hline 2 & $\begin{array}{l}\text { Durante as aulas práticas, você anota o passo a passo } \\
\text { dos procedimentos? }\end{array}$ & Cognitiva \\
\hline 3 & $\begin{array}{l}\text { Para memorizar uma técnica você costuma fazer } \\
\text { desenhos? }\end{array}$ & Cognitiva \\
\hline 4 & $\begin{array}{l}\text { Para aprender mais, você costuma fazer treino mental } \\
\text { das situações práticas? }\end{array}$ & Metacognitiva \\
\hline 5 & $\begin{array}{l}\text { Você costuma confrontar as práticas que você mesmo } \\
\text { pesquisa com os que lhes foram ensinados em aula? }\end{array}$ & Metacognitiva \\
\hline 6 & $\begin{array}{l}\text { Você costuma procurar por ilustrações e desenhos } \\
\text { quando está revisando as técnicas aprendidas? }\end{array}$ & Cognitiva \\
\hline 7 & $\begin{array}{l}\text { Você se distrai enquanto o professor ou os colegas } \\
\text { repetem uma técnica? }\end{array}$ & $\begin{array}{l}\text { Metacognitiva } \\
\text { disfuncional }\end{array}$ \\
\hline 8 & $\begin{array}{l}\text { Você cria situações simuladas para treinar as técnicas } \\
\text { aprendidas? }\end{array}$ & Metacognitiva \\
\hline 9 & $\begin{array}{l}\text { Para aprender melhor você pratica em casa as técnicas } \\
\text { que aprende na escola? }\end{array}$ & Metacognitiva \\
\hline 10 & $\begin{array}{l}\text { Você procura relacionar o conteúdo aprendido com } \\
\text { situações reais? }\end{array}$ & Metacognitiva \\
\hline 11 & $\begin{array}{l}\text { Ao fazer projetos para aplicar o conteúdo teórico à } \\
\text { prática você costuma ignorar as orientações do } \\
\text { professor quanto ao passo a passo a ser realizado? }\end{array}$ & $\begin{array}{l}\text { Metacognitiva } \\
\text { disfuncional }\end{array}$ \\
\hline 12 & $\begin{array}{l}\text { Você elabora checklist ou roteiros para as atividades } \\
\text { práticas que vai desenvolver? }\end{array}$ & Cognitiva \\
\hline 13 & $\begin{array}{l}\text { Você costuma acessar páginas de mídias sociais e } \\
\text { aplicativos como o Whatsapp durante as aulas? }\end{array}$ & $\begin{array}{c}\text { Metacognitiva } \\
\text { disfuncional }\end{array}$ \\
\hline
\end{tabular}

Com base na Tabela 1, observa-se que tanto os itens relacionados com as estratégias de aprendizagem cognitivas, como metacognitivas refletem as especificidades do EP por se referir à transferência do conteúdo aprendido nas aulas e às habilidades que são desenvolvidas para o contexto prático (Jossberger et al., 2019; Oliveira et al., 2019; Slaats et al., 1999). 0 uso efetivo destas estratégias de aprendizagem por parte dos alunos tende a favorecer 0 seu bom desempenho no curso (Santos \& Alliprandini, 2017; Scacchetti et al., 2015). Em contrapartida, os itens das estratégias metacognitivas disfuncionais refletem comportamentos que prejudicam o processo de ensino e aprendizagem no EP, principalmente a falta de atenção nas aulas e o acesso às redes sociais (Ganda \& Boruchovitch, 2016). 


\section{ESTUDO 2}

Neste estudo, os 13 itens elaborados no Estudo 1 para compor a EAVAP-EP foram submetidos à verificação de evidência de validade de conteúdo. Os 31 itens selecionados da EAVAP-EF não foram avaliados nem pelos juízes e nem no estudo piloto, por já possuírem esse tipo de validação reportada no manual do instrumento (Oliveira et al., 2010). Este estudo teve duas fases, nomeadamente a da análise dos juízes e a do estudo piloto.

\section{FASE 1 - ANÁLISE DOS JUÍZES: MÉTODO, RESULTADOS E DISCUSSÃO}

Participaram desta fase do estudo de adaptação da EAVAP-EP seis juízes. Todos os juízes possuíam Doutoramento, sendo quatro com especialidade em Psicometria e conhecimento sobre as estratégias de aprendizagem. Os outros dois eram doutores com experiência em estratégias de aprendizagem.

Nesta fase do estudo 2 foi usado um instrumento de coleta de dados, nomeadamente o Formulário de juízes (Pereira, 2016) - Os 13 itens construídos no Estudo 1 para compor a EAVAP-EP foram avaliados pelos juízes segundo a adequação da linguagem ao público-alvo (alunos do Ensino Profissionalizante), a adequação ao objetivo do instrumento (avaliar as estratégias de aprendizagem) e a indicação de novos itens. No formulário os juízes também classificaram os itens como pertencentes a uma das seguintes categorias: (a) estratégia cognitiva, (b) estratégia metacognitiva ou (c) estratégia metacognitiva disfuncional. Além disso, poderiam sugerir uma nova forma de estruturar a questão, caso o conteúdo lhes fosse incompreensível.

O convite de participação da pesquisa e o formulário de avaliação dos itens foi enviado para os juízes por e-mail. A participação dos juízes deu-se mediante o seu consentimento no TCLE. As respostas dos juízes foram analisadas com base na sua concordância e conteúdo. A comparação das respostas foi feita item a item. Excluíram-se os itens cuja concordância entre os juízes apresentasse um percentual inferior a 80 (Pasquali, 1999).

De entre os itens avaliados, 3 foram excluídos por apresentarem concordância abaixo de $80 \%$ por parte dos juízes (itens 4, 6 e 10 da Tabela 1). Outros três itens foram reformulados, dada a relevância que detinham nas descrições dos grupos focais e nas entrevistas com os professores enquanto estratégias específicas para o EP (itens 6, 7 e 9 da Tabela 2). Três itens que obtiveram concordância dos juízes superior a $80 \%$ também foram reformulados para melhor se adequarem ao aporte teórico, contexto e público-alvo avaliado, conforme indicam Scacchetti et al. (2015) quanto à necessidade de abordar as estratégias de aprendizagem o mais próximo possível da realidade do EP (itens 1, 4 e 10 da Tabela 2). Estes itens foram classificados pelos juízes de acordo com a compatibilidade teórica das estratégias de aprendizagem. Na classificação final, 4 itens foram alocados na dimensão cognitiva, 3 na dimensão metacognitiva e 3 na dimensão metacognitiva disfuncional. Os itens resultantes da análise de juízes são expostos na Tabela 2 . 
Tabela 2

Itens para a EAVAP-EP após a Análise de Juízes

\begin{tabular}{|c|c|c|}
\hline \multicolumn{2}{|r|}{ Itens } & Classificação \\
\hline 1 & $\begin{array}{l}\text { Para reforçar a aprendizagem você costuma assistir } \\
\text { vídeos online? }\end{array}$ & Cognitiva \\
\hline 2 & $\begin{array}{l}\text { Durante as aulas práticas, você anota o passo a passo } \\
\text { dos procedimentos? }\end{array}$ & Cognitiva \\
\hline 3 & $\begin{array}{l}\text { Para memorizar uma técnica você costuma fazer } \\
\text { desenhos? }\end{array}$ & Cognitiva \\
\hline 4 & $\begin{array}{l}\text { Você costuma confrontar os procedimentos técnicos } \\
\text { que você mesmo pesquisa com os que lhes foram } \\
\text { ensinados em aula? }\end{array}$ & Metacognitiva \\
\hline 5 & $\begin{array}{l}\text { Você se distrai enquanto o professor ou os colegas } \\
\text { repetem uma técnica? }\end{array}$ & $\begin{array}{l}\text { Metacognitiva } \\
\text { disfuncional }\end{array}$ \\
\hline 6 & $\begin{array}{l}\text { Você faz simulações para treinar as técnicas } \\
\text { aprendidas? }\end{array}$ & Metacognitiva \\
\hline 7 & $\begin{array}{l}\text { Você pratica em casa as técnicas que aprende na } \\
\text { instituição de ensino? }\end{array}$ & Cognitiva \\
\hline 8 & $\begin{array}{l}\text { Ao fazer projetos para aplicar o conteúdo teórico à } \\
\text { prática, você costuma ignorar as orientações do } \\
\text { professor quanto ao passo a passo a ser realizado? }\end{array}$ & $\begin{array}{c}\text { Metacognitiva } \\
\text { disfuncional }\end{array}$ \\
\hline 9 & $\begin{array}{l}\text { Você elabora roteiros para as atividades práticas que vai } \\
\text { desenvolver? }\end{array}$ & Cognitiva \\
\hline 10 & $\begin{array}{l}\text { Durante a aula você costuma acessar páginas de mídias } \\
\text { sociais e aplicativos como o WhatsApp, mesmo sem } \\
\text { relação com o conteúdo estudado? }\end{array}$ & $\begin{array}{l}\text { Metacognitiva } \\
\text { disfuncional }\end{array}$ \\
\hline
\end{tabular}

A partir da análise de juízes especialistas foi concluída a primeira etapa do presente estudo, respeitante à análise da evidência de validade de conteúdo da EAVAP-EP. Os resultados desta avaliação indicam que o conteúdo dos novos itens reflete as estratégias de aprendizagem cognitivas e metacognitivas para o Ensino Profissionalizante (AERA, APA, \& NMCE, 2014; Borsa \& Seize, 2017).

\section{FASE 2 - ESTUDO PILOTO: MÉTODO, RESULTADOS E DISCUSSÃO}

A amostra foi composta por 28 alunos dos Ensino Profissionalizante, matriculados nos últimos módulos do curso de técnico em Enfermagem, sendo $96,5 \%(n=27)$ do sexo feminino. Todos os alunos tinham o Ensino Médio completo. Os participantes apresentavam tempo médio de pausa entre o ensino regular e o curso profissionalizante de 4,05 anos, variando de zero a 12 anos de pausa entre o curso anterior e o atual.

Nesta fase do estudo 2 foi usado um instrumento de coleta de dados, nomeadamente o Formulário de Estudo Piloto contendo os novos itens elaborados na Fase 1 (vide Tabela 2) para compor a EAVAP-EP - Os alunos foram orientados a examinar a clareza e a compreensão da redação das sentenças e conteúdo dos itens, bem como dar sugestões de reescrita de itens e de substituição de palavras. 
A pesquisa ocorreu em sala de aula mediante a autorização dos docentes. Os alunos responderam ao Formulário de Estudo Piloto mediante a assinatura ao TCLE.

As respostas dos alunos ao Formulário de Estudo Piloto foram analisadas de forma quantitativa e qualitativa.

Os 10 itens avaliados pelos alunos apresentaram uma compreensão de $100 \%$, sugerindo que eles não tiveram dificuldades em compreendê-los. Este resultado indica que os alunos consideraram que as estratégias de aprendizagem cognitivas e metacognitivas nesses itens representam a rotina de estudos do EP, consoante com os estudos de Scacchetti et al. (2015). Estas estratégias também são compatíveis com as especificidades identificadas no processo de aprendizagem desta modalidade de ensino, centralizada no desenvolvimento e utilização de meios que possibilitem que o aluno consiga articular os aspetos teóricos com a prática (Brasil, 2018).

Os itens avaliados pelos alunos no estudo piloto foram somados aos 31 itens da EAVAP-EF para compor a EAVAP-EP, que ficou com 41 itens. Os resultados obtidos no estudo piloto acrescidos aos achados da análise de juízes indicam a evidência de validade de conteúdo à EAVAP-EP (AERA et al., 2014).

\section{ESTUDO 3: MÉTODO, RESULTADOS E DISCUSSÃO}

Participaram do estudo de evidência de validade de consistência interna 401 alunos de uma escola profissionalizante do interior paulista. Estes alunos eram dos cursos técnicos em Enfermagem, $n=164$ (40,9\%); Turismo, $n=23$ (5,7\%); Farmácia, $n=80$ (20\%); Administração, $n=42$ (10,5\%); Estética, $n=$ 56 (14\%), Moda, $n=10$ (2,5\%); Logística, $n=16$ (2,5\%) e Recursos Humanos, $n=16(4 \%)$. Destes alunos, $87,8 \%$ eram do sexo feminino $(n=352)$, com idade variando entre 18 e 67 anos $\operatorname{com}(M=27,29 ; D P=9,04)$. Quanto à escolaridade, 89,5\% ( $n=359)$ tinham Ensino Médio, 7,2\% $(n=29)$ Ensino Superior completo e 2,5\% $(n=10)$ Ensino Superior incompleto. 0 tempo de pausa nos estudos variou de 0 a 27 anos $(M=4,69 ; D P=5,64)$.

Nesta fase do estudo 3 foi usado um instrumento de coleta de dados, nomeadamente a Escala de Avaliação de Estratégias de Aprendizagem para o Ensino Profissionalizante (EAVAP-EP; Pereira \& Santos, 2016) - A versão adaptada da EAVAP-EF, a EAVAP-EP, possui 41 itens voltados para a avaliação das estratégias de aprendizagem de alunos do Ensino Profissionalizante. Estas estratégias referem-se às dimensões teóricas Ausência de Estratégias Metacognitivas Disfuncionais (16 itens), Estratégias Cognitivas (16 itens) e Estratégias Metacognitivas ( 9 itens). A chave de resposta é tipo Likert de três pontos - "2 = sempre", "1 = às vezes" e " 0 = nunca". Nos itens da dimensão teórica Ausência de Estratégias Metacognitivas Disfuncionais a pontuação deve ser invertida. No tocante à interpretação da escala, altas pontuações indicam maior uso de estratégias adequadas de aprendizagem e vice-versa. A pontuação mínima é de 0 pontos e máxima de 82 pontos. 
Seguiram-se todos os procedimentos éticos mencionados no Método do Estudo 1. Após os alunos assinarem o TCLE, a EAVAP-EP foi aplicada coletivamente e em horário de aula. 0 tempo médio de resposta ao instrumento foi de 15 minutos.

Os dados foram analisados por meio do software Statistical Package for Social Sciences (SPSS) - versão 22.0. Aplicaram-se as seguintes análises estatísticas: teste de Esfericidade de Barttlet; examinou-se o índice KaiserMeyer-Olklin (KMO); a análise de componentes principais - rotação Varimax, e a análise de consistência interna por meio do coeficiente alfa - índices interpretados com base em Murphy e Davidsholder (1988).

Anteriormente à análise fatorial exploratória, verificou-se a existência de correlação entre os itens da EAVAP-EP, por meio do teste de Esfericidade de Barttlet $=3472,186(p<0,001)$. A adequação da amostra foi averiguada pelo índice de KMO = 0,840. Por conseguinte, os 41 itens da EAVAP-EP foram submetidos à análise fatorial exploratória, por meio de diferentes métodos de extração, encontrando na análise de componentes principais com rotação Varimax a melhor solução.

Inicialmente, foram sugeridos 12 fatores com autovalores acima de 1,0 capazes de explicar $56,54 \%$ da variância total. Com a finalidade de confirmar a determinação do número de componentes a serem extraídos, foi utilizada a análise paralela, que indicou 5 componentes que explicaram $36 \%$ da variância da EAVAP-EP. Foram realizadas análises forçadas para 5 e 4 componentes; no entanto, os resultados encontrados não foram satisfatórios devido a falta de compatibilidade teórica dos itens nos dois componentes adicionais. Desse modo, a solução foi elaborada com três componentes conforme pressuposto teórico da escala original (EAVAP-EF).

Posteriormente, foi realizada uma nova análise de componentes principais com rotação Varimax forçada para três componentes que explicaram 28,98\% da variância, obtendo a distribuição dos itens por componentes. A partir dos índices obtidos com esta análise excluíram-se os itens cuja carga fatorial foi inferior à 0,30 (4 itens) e também os itens que carregaram fora do fator esperado, levando-se em conta o aporte teórico da escala (2 itens). Após a exclusão destes itens, realizou-se nova análise de componentes principais forçada para três fatores, que explicaram 31,47\% da variância da EAVAP-EP. Com base nos índices desta análise, 1 item foi excluído por apresentar carga fatorial inferior a 0,30. A partir da exclusão deste item, efetuou-se outra análise de componentes principais, cuja variância explicada da escala foi de $31,37 \%$ e a distribuição dos itens por componentes permaneceram dentro da composição teórica esperada e com cargas fatoriais acima de 0,30. Estes índices são apresentados nas Tabelas 3, 4 e 5. 
Tabela 3

Distribuição de itens que carregam no Componente Ausência de estratégias metacognitivas disfuncionais

\begin{tabular}{|c|c|c|}
\hline $\begin{array}{l}N^{\circ} \text {. do } \\
\text { item } \\
\text { original } \\
\end{array}$ & Itens & $\begin{array}{l}\text { Cargas } \\
\text { Fatoriais }\end{array}$ \\
\hline 25 & $\begin{array}{l}\text { Você costuma esquecer-se de fazer as coisas que seu professor } \\
\text { (a) pede? }\end{array}$ & 0,68 \\
\hline 26 & $\begin{array}{l}\text { Você costuma se distrair ou pensar em outra coisa quando está } \\
\text { lendo ou fazendo o dever de casa? }\end{array}$ & 0,63 \\
\hline 28 & Você costuma se esquecer de fazer o dever de casa? & 0,60 \\
\hline 36 & $\begin{array}{l}\text { Você se distrai enquanto o professor ou os colegas repetem } \\
\text { uma técnica? }\end{array}$ & 0,55 \\
\hline 12 & $\begin{array}{l}\text { Você se sente cansado quando lê, estuda ou faz o dever de } \\
\text { casa? }\end{array}$ & 0,54 \\
\hline 15 & $\begin{array}{l}\text { Você costuma ficar pensando em outra coisa quando o professor } \\
\text { (a) está dando explicações? }\end{array}$ & 0,50 \\
\hline 41 & $\begin{array}{l}\text { Durante as aulas você costuma acessar páginas de mídias } \\
\text { sociais e aplicativos, mesmo sem relação com o conteúdo } \\
\text { estudado? }\end{array}$ & 0,50 \\
\hline 8 & $\begin{array}{l}\text { Quando o seu professor (a) está explicando uma matéria nova, } \\
\text { você costuma ficar pensando em outra coisa }\end{array}$ & 0,50 \\
\hline 23 & $\begin{array}{l}\text { Depois que você senta para fazer a lição de casa, costuma ficar } \\
\text { se levantando toda hora para pegar algum material? }\end{array}$ & 0,48 \\
\hline 21 & $\begin{array}{l}\text { Quando você está fazendo uma tarefa difícil, costuma ficar } \\
\text { muito nervoso? }\end{array}$ & 0,47 \\
\hline 3 & $\begin{array}{l}\text { Você costuma estudar ou fazer o dever de casa na "última } \\
\text { hora"? }\end{array}$ & 0,44 \\
\hline 7 & Você costuma desistir quando uma tarefa é difícil ou chata? & 0,43 \\
\hline
\end{tabular}


Tabela 4

Distribuição dos itens que carregam no Componente Estratégias Cognitivas

\begin{tabular}{|c|c|c|}
\hline $\begin{array}{l}\mathrm{N}^{\circ} \text {. do } \\
\text { item } \\
\text { original } \\
\end{array}$ & Itens & $\begin{array}{l}\text { Cargas } \\
\text { Fatoriais }\end{array}$ \\
\hline 10 & $\begin{array}{l}\text { Quando você termina de estudar para uma prova, costuma fazer } \\
\text { questões para si próprio para ver se entendeu bem o que estudou? }\end{array}$ & 0,65 \\
\hline 11 & $\begin{array}{l}\text { Quando você lê um texto, procura escrever com suas palavras o } \\
\text { que entendeu da leitura, para poder estudar depois? }\end{array}$ & 0,63 \\
\hline 20 & $\begin{array}{l}\text { Você cria perguntas e respostas sobre o assunto que está } \\
\text { estudando? }\end{array}$ & 0,60 \\
\hline 38 & $\begin{array}{l}\text { Você pratica em casa as técnicas que aprende na instituição de } \\
\text { ensino? }\end{array}$ & 0,59 \\
\hline 5 & $\begin{array}{l}\text { Você costuma ler outros textos e livros sobre o assunto que o (a) } \\
\text { professor (a) explicou em aula? }\end{array}$ & 0,57 \\
\hline 9 & $\begin{array}{l}\text { Você costuma fazer um esquema usando as ideias principais do } \\
\text { texto? }\end{array}$ & 0,55 \\
\hline 17 & Você resume os textos que o professor (a) pede para estudar? & 0,54 \\
\hline 34 & Para memorizar uma técnica você costuma fazer desenhos? & 0,53 \\
\hline 4 & $\begin{array}{l}\text { Quando você está assistindo a uma aula, costuma anotar o que o } \\
\text { professor (a) está falando, mesmo quando ele (a) não manda ou } \\
\text { não escreve nada na lousa? }\end{array}$ & 0,51 \\
\hline 32 & Para reforçar a aprendizagem você costuma assistir vídeos online? & 0,48 \\
\hline 33 & $\begin{array}{l}\text { Durante as aulas práticas, você anota o passo a passo dos } \\
\text { procedimentos? }\end{array}$ & 0,46 \\
\hline 16 & $\begin{array}{l}\text { Quando você aprende uma coisa nova, costuma relacionar aquilo } \\
\text { que está aprendendo com alguma coisa que você já sabia? }\end{array}$ & 0,46 \\
\hline 40 & $\begin{array}{l}\text { Você elabora roteiros para as atividades práticas que vai } \\
\text { desenvolver? }\end{array}$ & 0,45 \\
\hline 1 & Você costuma grifar as partes do texto para aprender melhor? & 0,44 \\
\hline 14 & $\begin{array}{l}\text { Quando você estuda, lê a matéria e depois fecha o caderno e fala } \\
\text { em voz alta tudo o que entendeu? }\end{array}$ & 0,43 \\
\hline 2 & $\begin{array}{l}\text { Quando você está fazendo uma redação, costuma fazer uma lista } \\
\text { de ideias antes de começar a escrever? }\end{array}$ & 0,41 \\
\hline
\end{tabular}

Tabela 5

Distribuição dos itens que carregam no Componente Estratégias

Metacognitivas $-3^{a}$ análise

\begin{tabular}{|c|c|c|}
\hline $\begin{array}{c}\mathrm{N}^{\circ} . \text { do } \\
\text { item } \\
\text { original }\end{array}$ & Itens & $\begin{array}{c}\text { Cargas } \\
\text { Fatoriai } \\
\mathrm{s} \\
\end{array}$ \\
\hline 22 & $\begin{array}{l}\text { Quando você estuda, percebe se não está conseguindo } \\
\text { aprender? }\end{array}$ & 0,75 \\
\hline 13 & $\begin{array}{l}\text { Você percebe quando está com dificuldade para aprender } \\
\text { determinados assuntos ou matérias? }\end{array}$ & 0,75 \\
\hline 29 & Você percebe quando não entende o que está lendo? & 0,68 \\
\hline 6 & $\begin{array}{l}\text { Quando você estuda, costuma perceber que não esta } \\
\text { entendendo aquilo que está estudando? }\end{array}$ & 0,46 \\
\hline 27 & $\begin{array}{l}\text { Quando percebe que não entendeu o que leu, costuma parar } \\
\text { para ler novamente? }\end{array}$ & 0,33 \\
\hline
\end{tabular}


Após análise da estrutura interna dos itens da EAVAP-EP, foram estimados os índices de precisão da escala por meio do coeficiente alfa. Para o fator Ausência de Estratégias Metacognitivas Disfuncionais, $\alpha=0,78$, fator Estratégias Cognitivas, $\alpha=0,83$ e para o fator Estratégias Metacognitivas, $\alpha=$ 0,62 . A EAVAP-EP total obteve $\alpha=0,86$.

A variância explicada dos fatores que compõem a presente versão adaptada da EAVAP-EP foi consoante a escala original (Oliveira et al., 2010). Os itens da EAVAP-EP dispostos nas Tabelas 3, 4 e 5 são condizentes com o aporte teórico que fundamenta o instrumento e com a rotina de aprendizagem vivenciada pelos alunos do Ensino Profissionalizante (Brasil, 2018; Oliveira et al., 2019; Pozo, 1996; Scacchetti et al., 2015; Titon \& Zanella, 2018). O fator Estratégias Cognitivas representa o conteúdo referente ao ensaio, à elaboração e a organização utilizados pelos alunos durante os estudos e/ou atividades práticas. Do mesmo modo, os fatores Ausência de Estratégias Metacognitivas Disfuncionais e Estratégias Metacognitivas são condizentes com os componentes das estratégias metacognitivas, relativas ao planejamento, o monitoramento e a regulação do comportamento (Dembo \& Eaton, 2000; Oliveira et al., 2019; Oliveira et al., 2010). Em especial no que diz respeito ao fator Estratégias Metacognitivas, observou-se que a presente adaptação da EAVAPEF para o Ensino Profissionalizante obteve um índice de consistência interna ligeiramente maior $(\alpha=0,62)$ em comparação à versão adaptada do instrumento por Scacchetti et al. (2015), cujo coeficiente alfa foi de 0,57. Apesar de o índice de consistência interna ser igual ao da escala original (EAVAPEF; Oliveira et al., 2010), reconhece-se que este valor é considerado baixo, o que requer novas investigações deste índice em futuras pesquisas com a EAVAP-EP.

\section{CONSIDERAÇÕES FINAIS}

Este estudo promoveu a adaptação da EAVAP-EF para o EP - EAVAP-EP, e a averiguação das propriedades psicométricas deste instrumento, relativas à sua evidência de validade de conteúdo, evidências de validade baseada na estrutura interna e as estimativas de fidedignidade. Estes resultados sugerem que a EAVAP-EP pode ser utilizada por psicólogos, coordenadores pedagógicos e professores, entre outros profissionais envolvidos na Educação, para avaliar quais os tipos de estratégias de aprendizagem que os alunos do EP possuem mais ou menos desenvolvidas. Conjetura-se que os resultados dessa avaliação podem subsidiar a elaboração ou a revisão de práticas pedagógicas com a finalidade de desenvolver nos alunos a habilidade de empregar as estratégias cognitivas e metacognitivas para facilitar a aprendizagem do conteúdo das disciplinas, assim como aplicar o que é aprendido. Nesse sentido, o uso das estratégias de aprendizagem pode favorecer o desempenho dos alunos em atividades que envolvem a simulação dos exercícios práticos aplicados em sala de aula ou extra-aula, e também nos estágios, onde o aluno precisa utilizar os conhecimentos adquiridos durante a formação profissionalizante para exercer a profissão técnica. 
Apesar de o tempo de formação do EP ser mais curto quando comparado ao Ensino Superior, sugere-se que o desenvolvimento das estratégias de aprendizagem, principalmente as metacognitvas, além de contribuir para o desempenho académico dos alunos, também se traduz num meio de promover a sua autonomia. Neste sentido, aponta-se para a articulação entre o contexto do ensino com o trabalho, ao pressupor que os alunos que conseguem utilizar estratégias de aprendizagem compatíveis com aquilo que é solicitado nas atividades do curso também sejam mais conscientes sobre as habilidades que devem ser desenvolvidas para exercer a profissão. Assim sendo, o uso intencional das estratégias de aprendizagem e a autonomia pode contribuir para a inserção do aluno no mercado de trabalho, visto que é exigido cada vez mais a flexibilidade e a contínua capacitação dos profissionais.

Como sugestão de estudos futuros, sugere-se a investigação acerca do uso de estratégias de aprendizagem por parte dos alunos do EP, acrescida de outros construtos e habilidades ligados tanto ao ambiente académico como organizacional, como, por exemplo, a motivação, a adaptação ao curso e os motivos da evasão e permanência no EP. Uma vez que a EAVAP-EP apresentou propriedades psicométricas iniciais adequadas, aponta-se para a sua potencial contribuição para ampliar o conhecimento acerca do uso de estratégias de aprendizagem nessa modalidade de ensino. À vista disto, recomenda-se a continuidade das investigações das propriedades psicométricas deste instrumento, com o propósito de elevar a sua qualidade, o que beneficiará tanto a comunidade científica como os profissionais da prática, ambos atuantes no âmbito do EP. A divulgação dos resultados deste estudo, bem como a execução de futuras pesquisas com a EAVAP-EP denotam a relevância daquilo que é produzido no campo da Avaliação Psicológica e Educacional para a consolidação da Psicologia Escolar e Educacional como uma ciência, cujo conteúdo deve ser utilizado pelos profissionais da Psicologia para nortear e fundamentar a sua atuação no contexto do EP.

\section{AGRADECIMENTOS}

O presente trabalho foi realizado com apoio da Coordenação de Aperfeiçoamento de Pessoal de Nível Superior - Brasil (capes) - Código de Financiamento 001.

\section{REFERÊNCIAS}

American Educational Research Association, American Psychological Association, \& National Council on Measurement in Education, (2014). Standards for educational and psychological testing. American Educational Research Association.

Borsa, J. C., \& Seize, M. M. (2017). Construção e adaptação de instrumentos psicológicos: Dois caminhos possíveis. In B. F. Damásio \& J. C. Borsa (Orgs.). Manual de desenvolvimento de instrumentos psicológicos, (pp. 15-38). Vetor.

Boruchovitch, E. (1999). Estratégias de aprendizagem e desempenho escolar: considerações para a prática educacional. Psicologia Reflexão e Crítica, 12(2), 361-376. 
Brasil, Ministério da Educação. (2018). Educação Profissional Técnica de Nível Médio - Saiba Mais. Recuperado de encurtador.com.br/ksQV0

Brasil, Ministério da Educação. (2012). Resolução Nº 6, de 20 de setembro de 2012. Recuperado de encurtador.com.br/CMNX7

Brasil, Conselho Nacional de Saúde. (2016). Resolução CNS 510, de 07 de abril de 2016. Recuperado de http://conselho.saude.gov.br/resolucoes/2016/ Reso510.pdf

Cash, R. M. (2016). Self-regulation in the Classroom: Helping students learn how to learn. Free Spirit Publishing Inc.

Costa, E. R. D., \& Boruchovitch, E. (2015). O ensino de estratégias de aprendizagem no contexto da escrita. Psicologia da Educação, 41, 21-35. https://doi.org/10.5935/2175-3520.20150012

Cruvinel, M., \& Boruchovitch, E. (2004). Sintomas depressivos, estratégias de aprendizagem e rendimento escolar de alunos do ensino fundamental. Psicologia em Estudo, 9(3), 369-378.

Dembo, M. H., \& Eaton, M. J. (2000). Self-regulation of academic learning in middle-level schools. The Elementary School Journal, 100(5), 473-490.

https://doi.org/10.1086/499651

Flavell, J. H. (1979). Metacognition e Cognitive Monitoring: A new area of cognitive- developmental inquiry. American Psychologist, 34(10), 906-911.

Ganda, D. R., \& Boruchovitch, E., (2016). As atribuições de causalidade e as estratégias autoprejudiciais de alunos do curso de pedagogia. Psico-USF, 21(2), 331-340. https://doi.org/10.1590/1413-82712016210210

Gomes, M. A. M., \& Boruchovitch, E. (2005). Desempenho no jogo, estratégias de aprendizagem e compreensão na leitura. Psicologia: Teoria e Pesquisa, 21(3), 319-326.

Jossberger, H., Brand-Gruwel, S., van de Wiel, M. W., \& Boshuizen, H. P. (2019). Exploring Students' Self-Regulated Learning in Vocational Education and Training. Vocations and Learning, 1-28. https://doi.org/10.1007/s12186-019-09232-1

Kikas, E., \& Jõgi, A. (2015). Assessment of learning strategies: self-report questionnaire of learning task. European Journal Psychology of Education, 31(4), 579593. https://doi.org/10.1007/s10212-015-0276-3

Liu, O. L. (2009). Evaluation of a learning strategies scale for middle school students. Journal of Psychoeducational Assesment, 27(4), 1-11. https://doi. org/10.1177/0734282908327935

Murphy, K. R., \& Davidshofer, C. O. (1988). Psychological testing: Principles and applications. Prentice Hall.

Oliveira, K. L., Boruchovitch, E., \& Santos, A. A. A. (2010). EAVAP-EF - Escala de avaliação das estratégias de aprendizagem para o ensino fundamental. Casa do Psicólogo.

Oliveira, K. L., Boruchovitch, E., \& Santos, A. A. A. (2011). Estratégias de aprendizagem no ensino fundamental: Análise por gênero, série escolar e idade. Psico, 42(1), 98-105.

Oliveira, K. L., Santos, A. A. A., \& Inácio, A. L. M. (2017). Estratégias de aprendizagem no ensino médio brasileiro: Uma análise exploratória dos resultados. Revista de Estudios e Investigacion en Psicología y Educación, v/e(1), 337-341. https:// doi.org/10.17979/reipe.2017.0.01.3041 
Oliveira, R. R., Teixeira, L. A. A., \& Santos, M. E. D. A. S. (2019). Estratégias de aprendizagem e cursos de educação a distância: satisfação dos alunos matriculados e egressos em cursos profissionais. ForScience, 7(2), 1-25. https://doi.org/10.29069/ forscience.2019v7n2.e615

Pasquali, L. (1999). Psicometria - Teoria dos Testes na psicologia e na educação. Vozes.

Pereira, P. S. P., \& Santos, A. A. A. (2016). Escala de Avaliação de Estratégias de Aprendizagem para o Ensino Profissionalizante (EAVAP-EP). (Manuscrito não publicado). Universidade São Francisco, Itatiba, São Paulo.

Pereira, P. S. P. (2016). Parâmetros psicométricos de uma Escala de Avaliação de Estratégias de Aprendizagem para o Ensino Profissionalizante. (Dissertação de Mestrado). Universidade São Francisco, Itatiba, São Paulo.

Pozo, J. I. (1996) Estratégias de Aprendizagem. In C. Coll., J. Palacios \& A. Marchesi. Desenvolvimento Psicológico e Educação - Psicologia da Educação, (pp. 122-137). Artes Médicas.

Santos, D. A., \& Alliprandini, P. M.Z. (2017). Efeito de uma intervenção em estratégias de aprendizagem por infusão em alunos de biologia do Ensino Médio. Revista de Educación en Biología, 20(2), 52-72.

Scacchetti, F. A. P., Oliveira, K. L. D., \& Moreira, A. E. D. C. (2015). Estratégias de Aprendizagem no Ensino Técnico Profissional. Psico-USF, 20(3), 433-446.

Slaats, S. A., Lodewijks, H. G. L. C., \& Van der Saden, J. M. M. (1999). Learning styles in secondary vocational education: Disciplinary differences. Learning Instruction, 9(5), 475-492. https://doi.org/10.1016/S0959-4752(99)00007-9

Titon, A. P., \& Zanella, A. V. (2018). Revisão de literatura sobre psicologia escolar na educação profissional, científica e tecnológica. Psicologia Escolar e Educacional, 22(2), 359-368. https://doi.org/10.1590/2175-35392018010922

Informação dos autores:

i Universidade São Francisco, Campus de Campinas/SP, Brasil. https: //orcid.org/0000-0003-4911-3471

ii Universidade São Francisco, Campus de Campinas/SP, Brasil. https://orcid.org/0000-0002-8599-7465

iii Universidade São Francisco, Campus de Campinas/SP, Brasil. https: //orcid.org/0000-0002-9856-0094

Toda a correspondência relativa a este artigo deve ser enviada para:

Adriana Satico Ferraz

Rua Engenheiro Augusto de Figueiredo, 707, Apto $52 \mathrm{Bl} \mathrm{H,}$ Vila Progresso

Campinas, São Paulo, 13045-603, Brasil

adrianasatico.asegmail.com 
Learning strategies assessment scale for vocational education: Adaptation and psychometric studies

\begin{abstract}
This study aimed to investigate the psychometric properties of the Learning Strategies Assessment Scale for students in Vocational Education (EAVAPEP). We adapted this scale from Middle School to vocational education through a focal study with five teachers and 11 students. Through the expert judge's analysis and a pilot study with 24 students that evaluated the representativeness and comprehension of the adapted items of EAVAP-EP, we obtained the content validity of the EAVAP-EP. Afterwards, 401 students participated in the search for validity evidence based on EAVAP-EP internal structure. Principal component analysis indicated the explained variance of $31.37 \%$ of the instrument. EAVAP-EP presented 28 items divided into three dimensions: cognitive, metacognitive, and dysfunctional metacognitive. Factor loadings were above 0.30 . The EAVAP-EP reliability estimate was also verified (total scale: $\alpha=0.86$ ). We suggest the use of EAVAP-EP in the context of vocational education and the continuity of research with the instrument.
\end{abstract}

Keywords: Cognitive strategies; Metacognitive strategies; Psychoeducational assessment. 


\section{Escala de evaluación de estrategias de aprendizaje para la educación vocacional: Adaptácion y estudios psicométricos}

\section{RESUMEN}

Este estudio tuvo como objetivo investigar las propiedades psicométricas de la Escala de Evaluación de Estrategias de Aprendizaje para estudiantes de Educación Vocacional (EAVAP-EP). Adaptamos la escala del contexto de la educación básica a la educación vocacional a través de un estudio focal con cinco maestros y 11 estudiantes. A través del análisis de seis jueces expertos y un estudio piloto con 24 estudiantes que evaluó la representatividad y la comprensión de los elementos adaptados de EAVAP-EP, obtuvimos la validez de contenido del EAVAP-EP. Posteriormente, 401 estudiantes participaron en la investigación de evidencia de validez basada en la estructura interna EAVAP-EP. El análisis del componente principal indicó la varianza explicada del $31,37 \%$ del instrumento. EAVAP-EP presentó 28 ítems divididos en tres dimensiones, a saber, cognitiva, metacognitiva y metacognitiva disfuncional. Las cargas factoriales fueran superiores a 0,30. También se verificó la estimación de fiabilidad EAVAP-EP (escala total: $\alpha=$ 0,86 ). Sugerimos el uso de EAVAP-EP en el contexto de la educación vocacional y la continuidad de la investigación con el instrumento.

Palabras clave: Estrategias cognitivas; Estrategias metacognitivas; Evaluación psicoeducativa. 